\title{
Bel ağrısında tanı ve tedavi algoritması
}

\section{Algorithm of the diagnosis and management of the low back pain}

\author{
Vugar Nabiyev¹, Selim Ayhan², Emre Acaroğlu ${ }^{1}$ \\ ${ }^{1}$ Ankara Acıbadem Artes Omurga ve Omurilik Merkezi, Ortopedi ve Travmatoloji, Ankara \\ ${ }^{2}$ Ankara Acıbadem Artes Omurga ve Omurilik Merkezi, Beyin ve Sinir Cerrahisi, Ankara
}

Bel ağrısı, ağrı ve maluliyetin sık karşılaşılan nedenlerinden bir tanesidir. Bireylerin çoğu, hayatlarının bir döneminde bel ağrısı ile karşılaşmaktadırlar. Çoğu olguda spesifik etiyoloji ortaya konulamazken, altta yatan risk faktörlerinin belirlenmesi ve bel ağrısında kırmızı bayrak olarak adlandırılan belirtilerin analiz edilmesi, kronik bel ağrısının ileri tetkik ihtiyacını ortaya koymada, tedavisinin planlanmasında ve kronikleşmenin engellenmesinde önemli rol oynamaktadır. Bu derlemede, bel ağrısı hastalarının değerlendirilmesi, sınıflandırılması ve tedavilerinin planlanması aşamasında üstlenilecek roller ve yapılması gerekenler irdelenecektir.

Anahtar sözcükler: bel ağrısı; tanı; tedavi; algoritma
Low back pain is a common cause of pain and disability. Most of the individuals may experience low back pain at least once in his/her lifetime. Although the specific etiology cannot be assessed in most cases, identifying the risk factors and red flags is crucial for the need for further evaluation, treatment planning, and avoidance of chronic low back pain. Here, the authors briefly review the physicians' role in evaluating, classifying and treating low back pain patients.

Key words: low back pain; diagnosis; treatment; algorithm
B el ağrısı (BA), günümüzde toplumda görülen ağrı ve maluliyetin sık karşılaşılan nedenlerinden birisi olup, yıllık tedavi maliyeti, Amerika Birleşik Devletleri'nde yapılan bir araştırma sonucuna göre milyon dolarları aşmaktadır. ${ }^{[1]}$ Dünyada, erişkin çağda BA sıklığını değerlendiren epidemiyolojik çalışmalar, prevalansın anlık \%12, aylık \%23, yıllık \%38 ve yaşam boyu yaklaşık $\% 40$ olduğunu ortaya koyarken, ${ }^{[2]}$ ülkemizde yaşam boyu prevalans, kentsel yerleşim bölgelerinde \%50'lere, kırsalda ise \%80'lere ulaşmaktadır. ${ }^{[3-5]}$ Yaşlanan nüfusla birlikte sıklığı artan ve önemli bir halk sağlığı problemi olarak da görülen bu durum, hekimlere başvurunun ikinci, bir sağlık kurumunda yatarak tedavi edilen hastalıklar içerisinde beşinci ve cerrahi olarak tedavi edilen hastalıklar içerisinde ise üçüncü en sık neden olarak karşımıza çıkmaktadır. ${ }^{[6,7]}$

Klasik olarak, kostal alt sınır ile inferior gluteal kıvrımların üstü arasındaki kas gerginliği-katıllğı olarak da tanımlanan BA'ya, bacak ağrısı yani siyatalji de eşlik edebilir. Yakınmaların süresine göre BA olguları; akut ( $<1$ ay), subakut (1-3 ay) ve kronik ( $>3$ ay) olarak gruplandırılır. Lomber disk herniyasyonu, enfeksiyon, inflamasyon, osteoporoz, romatoid artrit, kırık ya da neoplazi gibi spesifik bir patofizyolojik mekanizma neticesinde BA ortaya çıkabileceği gibi -ki bu ancak hastaların \%10'unda görülür- ${ }^{[8]}$ non-spesifik, yani belirli bir etmen olmadan da BA izlenebilir. Radyografik olarak ortaya konulan omurga patolojilerinin non-spesifik BA ile ilişkili olmayabileceği, herhangi bir semptom olmadan da söz konusu radyolojik değişikliklerin toplumda azımsanmayacak oranda görülebileği akılda tutulmalıdır. ${ }^{[9]}$ Aynı zamanda, söz konusu görüntüleme tetkiklerinin endikasyon olmadan elde edilmesinin, klinik sonuçları değiştirmeyeceği de bilinmelidir. ${ }^{[10]}$

Derlemede BA ile ilgili güncel bilgilerin paylaşılmasının yanı sıra, BA hastalarının değerlendirilmesi, sınıflandırılması ve tedavilerinin planlanması aşamasında üstlenilecek roller ve yapılması gerekenler irdelenecektir.

- Illetişim adresi: Prof. Dr. Emre Acaroğlu, Ankara Acıbadem ARTES Omurga ve Omurilik Merkezi, İran caddesi 45/2 Kavaklıdere, Ankara

Tel: 0312 - 4670442 e-posta: acaroglue@gmail.com

- Geliş tarihi: 17 Ağustos 2015 Kabul tarihi: 17 Ağustos 2015 


\section{ETIYOLOJi VE RISK FAKTÖRLERI}

Bel ağrılarının büyük çoğunluğu mekanik kaynaklı olup, ${ }^{[11,12]}$ omurga ile etrafındaki yapıların aşırı kullanılması, zorlanması ya da travmatize olması neticesinde gelişen klinik tablo, mekanik bel ağrısı olarak adlandırılmaktadır. Bu tip ağrıların büyük çoğunluğunda özgül etiyoloji tam olarak belirlenememektedir; disk, paraspinal adaleler, bağlar vb. dokulardaki dejenerasyon, gerilme ve burkulmalar ağrıdan sorumlu tutulmaktadır. BA'yı mekanik olarak tanımlayabilmek için, inflamatuvar, enfeksiyöz, neoplastik ve metabolik nedenler ile fraktür ve iç organlardan yansıyan ağrılar gibi tüm diğer organik -spesifik- nedenler dışlanmalıdır. ${ }^{\left[{ }^{13}\right]}$ Mekanik BA'da, omurgaya yük binmesiyle ağrı oluşur. Genellikle fiziksel aktivite, uzun süre ayakta kalma ya da uzun süre oturma ile ağı artarken, istirahat ile azalır. Daha çok dejeneratif ve travmatik sorunlar neticesinde ortaya çıkan bu ağı tipi, sıklıkla bele lokalize olmakla beraber, zaman zaman kalça ve uyluklara da yayılabilir. ${ }^{[5,8]}$

\section{RISK FAKTÖRLERI}

\section{Kişisel}

Yaş (ilk atak genellikle 25-30 yaşlarda izlenir ve ortalama 55 yaş civarında daha sık görülür), cinsiyet (erkek; 60 yaş sonrası - postmenopozal - kadınlar), ırk (beyaz ırk), genetik yatkınlık, vücut ağırlığı (obezite), uzun boy, tütün kullanımı, postüral faktörler, omurga hareket açıklığının kısıtlı oluşu, kas gücü zayıflığı, fizik kondüsyon yetersizliği/düşük egzersiz kapasitesi, psikososyal ve emosyonel durum (stres, depresif duygulanım, somatizasyon) ile düşük sosyoekonomik düzey, kişisel faktörler içerisinde sayılabilir. ${ }^{[7,14]}$

\section{Meslekle ilgili}

Ağır kaldırma, itme, burkulma, uzun süre oturma, vibrasyona maruz kalma ve uzun çalışma süresi, BA'dan yakınma oranını arttıran etkenlerdir. Bunun yanı sıra, işlerini monoton, sıkıcı ve tatminkar bulmayanlarda da BA'dan yakınma oranı daha yüksektir. ${ }^{[7]}$

\section{KLINIK DEĞERLENDIRME}

Hastaların sınıflandırılması ve gerekli ise uzman hekime yönlendirilmesi aşamasında iyi bir klinik değerlendirme kaçınılmazdır. Böylelikle, problemin basit bir bel ağrısı mı yoksa sinir kökü ağrısı, ciddi bir spinal patoloji (kırmızı bayraklar) ya da kauda ekina sendromu mu olduğu ortaya konulmalı ve probleme yönelik olarak sevk ya da tedavi planlanmalıdır. Bu bağlamda, eksiksiz öykünün alınması, klinik değerlendirmenin ilk ve en önemli basamağıdır.

\section{Öykü}

Bel ağrısını başlatan mekanizma, ağrının şiddeti, yayılımı, şekli ve süresinin yanı sıra, postür - aktivite ile ilişkisi, gün - zaman içerisindeki seyri, ağrıyı arttıran ve azaltan faktörler sorgulanmalıdır. Eşlik edebilecek ateş, gece terlemesi, kilo kaybı, çarpıntı, halsizlik, bulantı, kusma, sabah tutukluğu, istirahat sonrası katılığı, his kusuru, kuvvet kaybı, idrar yapma ya da dışkılama ile ilgili problemler vb. belirtiler de kayıt altına alınmalıdır. Ayrıca, travma öyküsü, sigara kullanımı, meslekle ilgili faktörler ve hastanın özgeçmişinde osteoporoz, diabetes mellitus, kanser, artrit, inflamatuvar barsak hastalığı ve/veya diğer sistemik hastalıkların varlığı; kırık öyküsü ve kortikosteroid ya da immünsupresif ilaç kullanımı öyküsü varlığı da bilinmelidir. ${ }^{[7]} \mathrm{Bu}$ aşamada, değerlendirmedeki en önemli basamak, BA'da kırmızı bayrak olarak adlandırılan belirtileri, yani neoplastik sorunlar, enfeksiyon, travma, sistemik hastalıklar vb. patolojilerden dolayı nöral doku basısı izlenebilecek olguları ortaya çıkarmaktır (Tablo 1). ${ }^{[15,16]}$ Bu hastalar, her ne kadar tüm BA nedenleri içerisinde oldukça küçük bir grubu oluştursalar da; tanınmadıkları zaman morbidite ve mortalite oranlarının yükselmesine neden olabilmelerinden ötürü, erken tanısal testlere tabi tutularak altta yatan hastalığa özgül tedavi planlanmalıdır. [5] Öyküde aynı zamanda hastanın psikososyal durumu da değerlendirilmeli, hastalığın prognozu açısından önemli olabilecek stres, anksiyete, negatif duygulanım, iş memnuniyeti, aile özellikleri ve hasta beklentileri vb. faktörler de açığa çıkarılmalıdır. ${ }^{[7,17]}$

\section{Fizik İnceleme}

Genellikle tek başına kesin bir tanıya götürmemekle birlikte, dikkatli fizik ve nörolojik inceleme, bel ağrılarının olası ciddi nedenlerini ortaya koymada yardımcı olur (Tablo 1).

\section{inspeksiyon}

İnspeksiyon ile lomber lordozda artma ya da azalma veya skolyoz varlığı ortaya konabilir. Skolyoz omurga ve gögüs kafesinde yapısal değişikliklerle birlikte izlenebileceği gibi; paravertebral kas spazmı ya da bacaklarda uzunluk farkına ikincil, fonksiyonel olarak da görülebilir. Lomber bölgede kıllanmanın izlenmesi, konjenital spinal malformasyonlar için belirleyici olabilir. Dermatomal dağılımda tipik cilt lezyonunun görülmesi, zona zoster tanısı için patognomoniktir. ${ }^{[7]}$

\section{Palpasyon}

Palpasyon ile spinöz çıkıntılar, bağlar ve paravertebral adaleler değerlendirilebilir. Spinöz çıkıntı hassasiyeti, travma, tümör veya enfeksiyon olgularında kırık/ patolojik kırık ihtimalini akla getirir. Komşu spinöz 
Tablo 1. Bel ağrısı ve radiküler ağrı öyküsü olan hastalarda kırmızı bayraklar ${ }^{[5]}$

\begin{tabular}{|c|c|}
\hline Kırmızı Bayrak & Klinik Anlam \\
\hline \multicolumn{2}{|l|}{ Öykü } \\
\hline Yaş<15 & Doğumsal ve kazanılmış hastalıklar, spondilolistezis \\
\hline Yaş $>55$ & Malignensi, patolojik fraktür, enfeksiyon, AAA \\
\hline$<3$ ay gelişen semptomlar & Daha ciddi etiyoloji \\
\hline Travma & Fraktür \\
\hline Ateş, titreme, yorgunluk, gece terlemesi, kilo kaybı & Malignensi, osteomiyelit, abse, fraktür \\
\hline $\begin{array}{l}\text { Kanser öyküsü, HIV varlığı, steroid kullanımı, IV ilaç alımı, } \\
\text { immünosupresyon }\end{array}$ & Malignensi, osteomiyelit, abse, fraktür \\
\hline Uyumsuz ağrı & Malignensi, osteomiyelit, abse, fraktür \\
\hline $\begin{array}{l}\text { Üriner retansiyon, gaita inkontinansı, eyer tip anestezi, bilateral } \\
\text { nörolojik yakınmalar }\end{array}$ & Kauda ekina basısı \\
\hline \multicolumn{2}{|l|}{ Fizik Muayene } \\
\hline Ateş & Malignensi, osteomiyelit, abse \\
\hline $\begin{array}{l}\text { Bilateral nörolojik bulgular (motor kuwetsizlik, azalmış refleksler), } \\
\text { eyer tip anestezi, anal sfinkter kuwvetsizliği }\end{array}$ & Kauda ekuina basısı \\
\hline Spinöz çıkıntı hassasiyeti & Fraktür \\
\hline
\end{tabular}

çıkıntılar arası basamaklanmanın olması ise spondilolistezisi düşündürür. Yaygın ve çok fazla (tetik) nokta hassasiyetinin varlığı fibromiyaljiye ikincil gelişen BA'nın bulgularındandır.

\section{Hareket Açıklığının Değerlendirilmesi}

Hareket açıklığının değerlendirilmesi, mobil omurga incelemesinin bir diğer olmazsa olmazıdır. Bel hareketlerinin ağrılı olması ve hareket kısıtlılığının varlığı tüm akut BA olgularında izlense de; öne eğilmekle artan ağrı kaslar, bağlar, disk kökenli patolojiler ve kompresyon kırıklarını akla getirirken (anterior yerleşimli patoloji), ekstansiyonda artan ağrı ise faset eklem proble$\mathrm{mi}$, spinal stenoz ya da spondilolistezis için (posterior yerleşimli patoloji) ipucu oluşturur. ${ }^{[7]}$ Lomber intervertebral eklem hareketlerinin kısıtlanması, spondiloartropati olgularında izlenebilir ve Schober testi ile doğrulanabilir. Hareket açıklığı ölçümünün, tedavi sonuçlarının takibi açısından önemli olduğu unutulmamalıdır. ${ }^{[18]}$

Kalça eklemleri de fizik incelemeye dahil edilmeli, sakroiliak manevralar ile FABERE (fleksiyon, abduksiyon, eksternal rotasyon, ekstansiyon) ve FADIR (fleksiyon, adduksiyon, iç rotasyon) testleri de uygulanmalıdır. Osteoartrit olgularında azalmış eklem hareket açıklığının kalça ve bel ağrılarına neden olabileceği bilinmelidir. BA ile karışabilen trokanterik bursitin, trokanter majör üzerinde hassasiyet ile bulgu verdiği akılda tutulmalıdır.
Siyataljinin eşlik ettiği BA olgularında, sinir germe testleri kök basısına işaret edebilir. Düz bacak kaldırma testi ve Laseque testi L4-L5 ve L5-S1 disk herniyasyonları için duyarlı kabul edilirken, santral spinal stenoz olgularında söz konusu testler genellikle negatiftir. Çapraz düz (karşı) bacak kaldırma testi ise disk herniyasyonu için özgül fakat duyarlı olmayan bir inceleme bulgusu olup, özellikle sinir kökü aksillasında yerleşim gösteren disk herniyasyonları ile ilişkili olduğu kabul edilmektedir. ${ }^{[8,19-21]}$ L3 ve $L 4$ kök basısı varlığında ise, belden uyluk ön yüzüne yayılan ağrı ile karakterize olan femoral sinir germe testi sıklıkla pozitiftir.

Sinir kökü basısı varlığının değerlendirilebilmesi, ayrıntılı bir nörolojik inceleme ile mümkündür (Tablo 2). ${ }^{[7]}$ Ayrıca, eşlik edebilecek kas atrofisi varlı̆̆ ral uyluk ya da baldırın çevre ölçümü ile teyit edilir. ${ }^{[18]}$

Psikosomatik köken varlığında, ağrı olduğundan daha abartılı izlenebilir ve yakınmalar ile muayene bulguları örtüşmeyebilir. Bu bağlamda, incelemede uygulanan Waddell testlerinin beş bulgusundan (muayeneye aşırı reaksiyon, yüzeyel dokunma ile hassasiyet, nöroanatomik yapılara uymayan bölgesel duyu - motor bulgular, normalde ağrı oluşturmayan hareketlerin ağrı oluşturması [kafaya baskı ile ya da omuzların ve pelvisin rotasyonu ile], doğrulayıcı testlerde çelişkili sonuçlar [düz bacak kaldırma testinin oturarak yapıldığında ağrısız olması]) en az üçünün var olması, organik kökeni olmayan bel ağrısı açısından klinik anlam 
Tablo 2. Sinir kökü basısına bağlı nörolojik muayene bulguları

\begin{tabular}{lllll}
\hline Sinir kökü & Kuvvet kaybı & Duyu kaybı & Refleks kaybı & Hasta ne yapmakta zorlanır? \\
\hline L4 & Diz ekstansiyonu & Ayak mediyali & Patella & Çömelme/kalkma \\
L5 & Ayak ve başparmak dorsifleksiyonu & Ayak dorsal yüzü & & Topuklarda yürüme \\
S1 & Plantar fleksiyon & Ayak plantar yüzü ve laterali & Aşil & Parmak ucunda yürüme
\end{tabular}

Tablo 3. Kauda ekina sendromunun klinik belirti ve bulguları

Öykü
Her iki alt ekstremitede radiküler ağrı (bir tarafta daha fazla
olabilir)
İzole bel ağrısı (nadir)
Bacak(lar) ve ayak(lar)da kuvvetsizlik ve yürüme bozukluğu
İdrar retansiyonu nedeniyle karında rahatsızlık hissi, ağrı,
boşaltma güçlüğü
Katı ile gazı ayırt edememe
Nörolojik muayene
Alt ekstremitelerde motor ve duyu kayıp
Alt ekstremite reflekslerinde azalma
Düz bacak kaldırma ve çapraz düz (karşı) bacak kaldırma testi
pozitifliği
Eyer tip anestezi
Sfinkter tonusunda azalma
Üriner retansiyon

teşkil eder. ${ }^{[22]}$ Yine bu amaçla, Blom ve arkadaşlarının tanımladığı topuk tıklatma (heel-tap) testi de uygulanabilir. ${ }^{[23]}$

Fizik ve nörolojik incelemede ayırt edilmesi gereken bir diğer önemli husus da, kauda ekina sendromunun varlığıdır. Lumbosakral bölgede, kauda ekina bölgesini içeren spinal sinir köklerinin akut basıya uğraması sonrası görülen bu nörolojik tablonun öykü ve fizik muayene bulguları Tablo 3'te özetlenmiştir. Bu durum, daha önce de ifade edildiği gibi, BA için diğer bir kırmızı bayrak olup, varlığı acil müdahele gerektirir. Kauda ekina sendromu benzeri bulguların, servikal ya da torakal bölgede spinal kord kompresyonuna bağlı olarak da görülebileceği akılda tutulmalıdır. ${ }^{[24]}$

\section{TANISAL TESTLER}

\section{Görüntüleme Tetkikleri}

Direkt radyografi, birinci basamakta da uygulanabilen en basit ve en ucuz yöntem olmasının yanın$\mathrm{da}$, günümüzde $\mathrm{BA}$ incelemesinde kullanılan en sık görüntüleme çalışmasıdır. ${ }^{[5,7]}$ Kırık ya da deformite çağrıştıran kırmızı bayraklar varlığında yeri oldukça değerli iken, kemik yıkımının başlamamış olduğu enfeksiyon ve neoplazi olgularında yeterli olmayabilir (Şekil 1). ${ }^{[5]}$ Aynı zamanda, akut BA'da kırmızı bayraklar yok ise, elde edilmesine gerek de olmadığı bilinmelidir. Kesitsel görüntüleme tetkiklerinden bilgisayarlı tomografi (BT) ince kemik ayrıntısı göstermede üstünken, manyetik rezonans (MR) görüntüleme, yüksek yumuşak doku çözünürlüğü sayesinde, disk problemleri, kemik iliği lezyonları, paravertebral adaleler ve bağların hastalıklarının ortaya konulmasında; benign ve malign neoplastik lezyonların, yeni ve eski osteoporotik kırıkların, spesifik ve spesifik olmayan enfeksiyonların ayrımında ve patofizyolojik değişikliklerin tanımlanmasında yardımcıdır. ${ }^{[5,7,24]}$ Tanıda altın standart olan bu görüntüleme yöntemi; kırmızı bayraklar varlığında, progresif nörolojik kaybın eşlik ettiği durumlarda, altı haftadan uzun süreli konservatif tedaviye yanıt alınamayan olgularda endikedir. Kesitsel görüntüleme yöntemlerine, invaziv girişim ya da cerrahi tedavi uygulanacak olgularda işlem öncesi anatomik ayrıntının ortaya konulması, klinik ile ilişkili seviyenin değerlendirilmesi ve yapılacak girişimin gerekliliğinin gözden geçirilmesi aşamalarında da ihtiyaç duyulur (Şekil 2-4). ${ }^{[7,25]}$ Sintigrafik çalışmalar, yüksek duyarlılıklarının yanında düşük özgüllükleri ile, kesin tanı - ayııı ı tanı aşamalarında yardımcı değildir. ${ }^{[5,7]}$

Görüntüleme yöntemlerinin önemli bir problemi, BA olan olgularda görülen anatomik anormalliklerin, asemptomatik bireylerin $\% 75^{\prime}$ ten fazlasında izlenebilmesidir. ${ }^{[18,26]}$ Dolayısıyla, yukarı bahsedilen endikasyonlar haricinde radyolojik tetkiklerin elde edilmesinin, hekimi yersiz bir karmaşa içerisine sürükleyebileceği akılda tutulmalıdır. ${ }^{[7]}$

\section{Elektrofizyolojik Çalışmalar}

Sinir iletim çalışmaları bazı lumbosakral radikulopatili olguların değerlendirilmesine yardımcı olmaktadır; sinir kökü basısı varlığı, var ise süresi ve şiddeti teyit edilmektedir. Böylelikle, nörofizyoloji ortaya konulmakta ve görüntüleme tetkikleri ile elde edilen bulgular desteklenmekte ya da doğrulanmamaktadır. Bu nedenle, 
özellikle klinik bulgular ile görüntüleme yöntemleri arasında tutarsızlık olan ve eşlik eden radikülopatisi olan olgularda, söz konusu yöntemlere başvurulmaktadır. Ayrıca, L5 radikülopatisi olan hastalarda, peroneal sinir paralizisi veya lumbosakral pleksopatinin ayırıcı tanısında da, sinir iletim çalışmaları yardımcı olmaktadır. Elektromiyografik değişikliklerin, sinir hasarını takiben kas denervasyonunun gelişmesi neticesinde ortaya çıtığı ve yaklaşık 2-3 hafta süreceği bilinmeli, söz konusu değişikliklerin bir yıl boyunca değişmeden kalabilme ihtimalinin olduğu ise akılda tutulmalıdır. ${ }^{[27]}$

\section{Laboratuvar Testleri}

BA hastalarında, özellikle kırmızı bayrak belirtilerinin eşlik ettiği olgularda, laboratuvar testleri tanı konulmasına yardımcı olur. Beyaz küre sayımı, eritrosit sedimentasyon hızı, C reaktif protein enfeksiyon tanısında; spesifik tümör belirteçleri de neoplastik olguların ayırıcı tanısında yardımcı olmaktadır. ${ }^{[5,7]}$

\section{AYRICI TANI}

"Etiyoloji ve Risk Faktörleri” başlığında da belirtildiği üzere, BA genellikle omurga ile etrafındaki kaslar ve ligamentöz dokulardan kaynaklanmakta olup, hastaların önemli kısmında mekaniktir. Bu olgularda radyolojik çalışmalar ile ortaya konan disk dejenerasyonu, disk herniyasyonu, spondilozis, spondilolistezis,
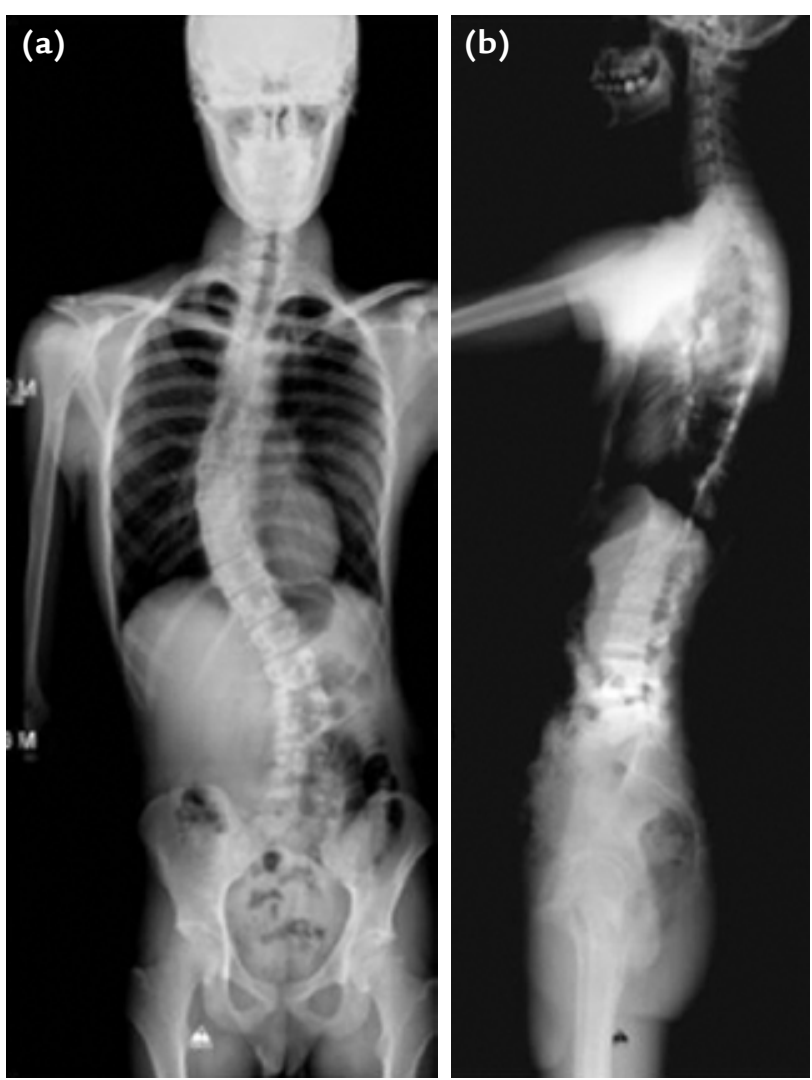

Şekil 1. a, b. Sırtında eğrilik ve bel ağrısı yakınması ile başvuran 17 yaşındaki erkek hastanın anteroposterior (a) ve lateral (b) direkt grafilerinde skolyoz görüntüsü.
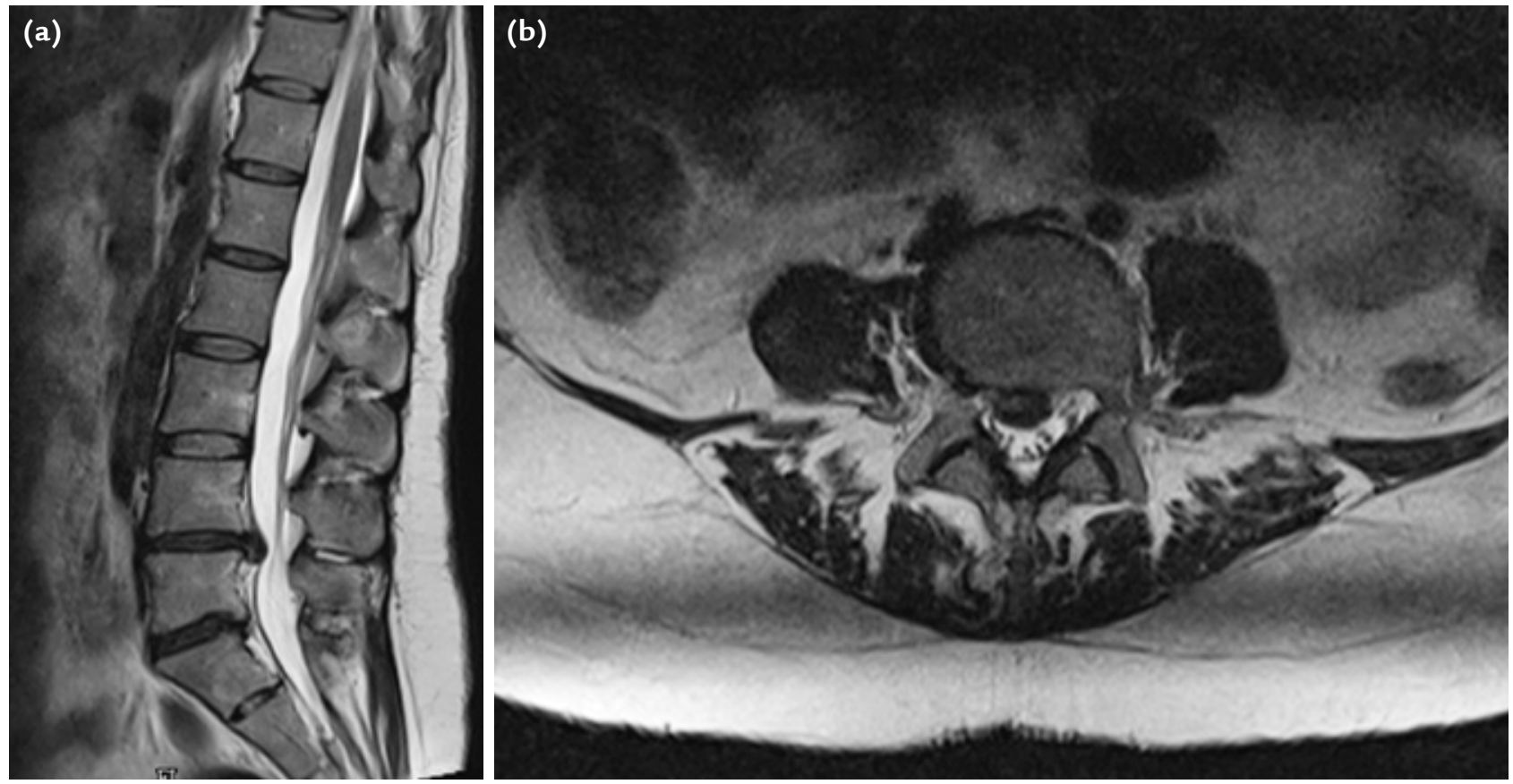

Şekil 2. a, b. Bel ağrısı, sağ kalça ve bacak ağrısı yakınmaları ile başvuran, nörolojik incelemesinde sağ ayak ve başparmak dorsifleksiyonunda kuvvet defisiti ile sağda $20^{\circ}$ 'de müspet Laseque testi saptanan 31 yaşındaki kadın hastanın T2 ağırlıklı sagittal (a) ve aksiyel (b) MR görüntüleme tetkikinde, L4-5 düzeyinde ekstrude disk hernisi görünümü. 

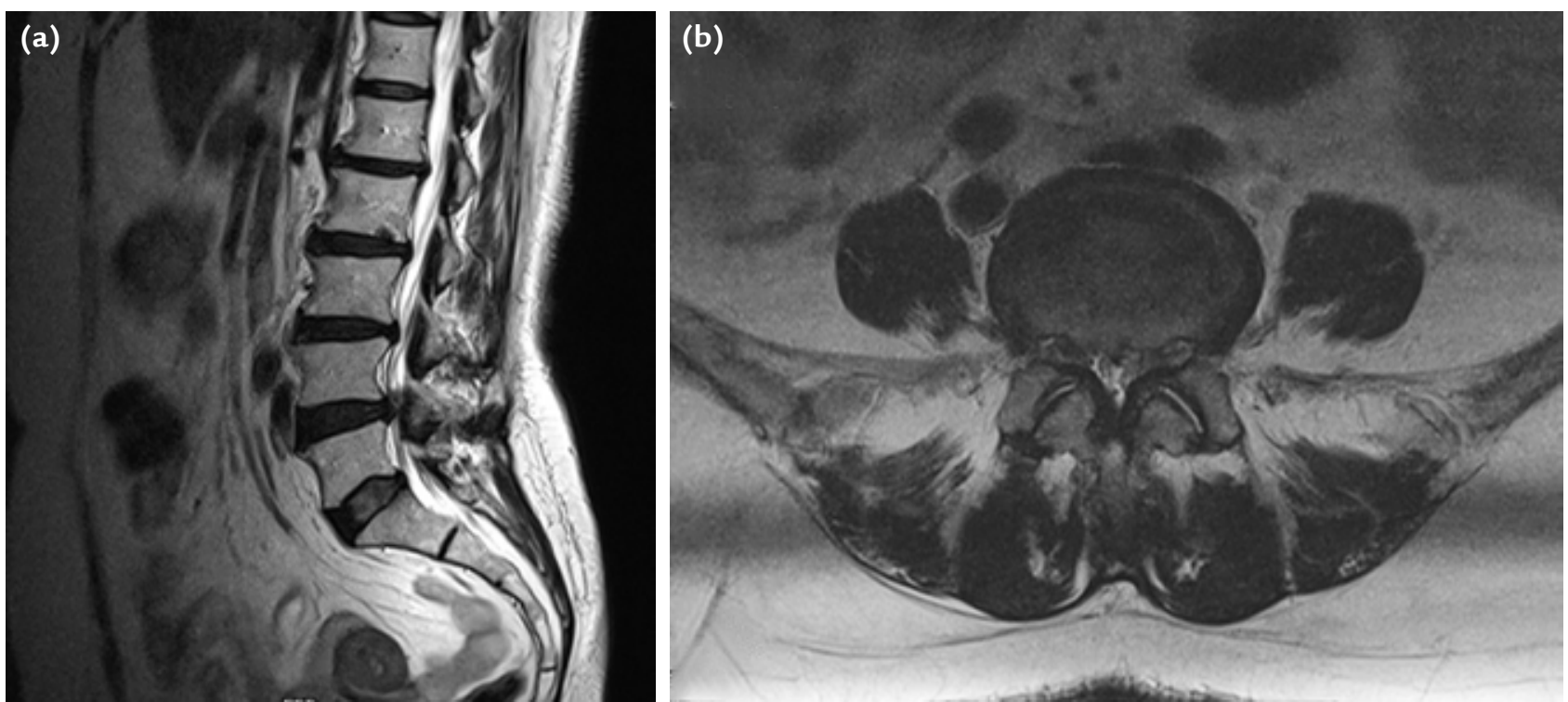

Şekil 3. a, b. Bel ağrısı, sol kalça ve bacak ağrısı, sol ayakta yürürken takılma yakınmaları ile başvuran, nörolojik incelemesinde solda ayak ve başparmak dorsifleksiyonunda kuvvet defisiti saptanan 69 yaşındaki kadın hastanın T2 ağırlıklı sagittal (a) ve aksiyel (b) MR görüntüleme tetkikinde, L4-5 düzeyinde santral ve foraminal stenoz görüntüsü.
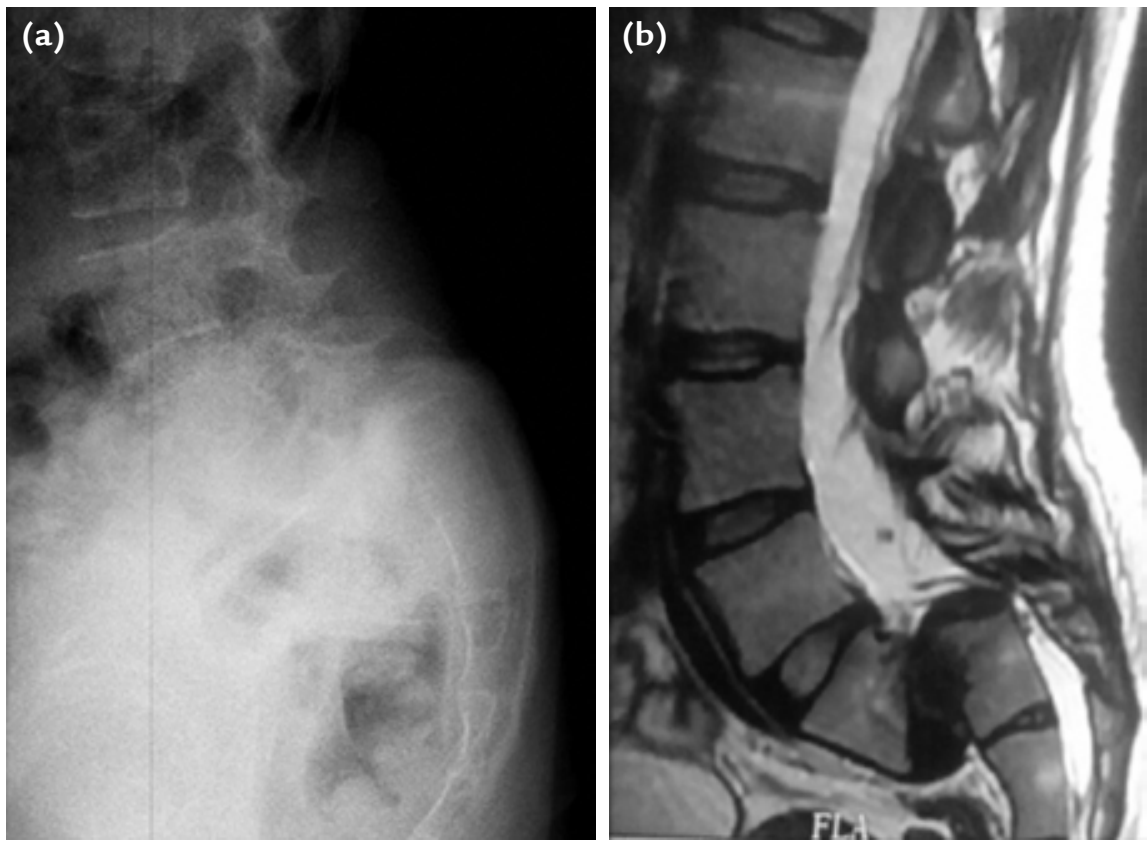

Şekil 4. a, b. Bel ağrısı ve bilateral bacak ağrısı yakınması ile başvuran, nörolojik incelemede motor veya duyu kusuru saptanmayan, ancak her iki bacakta da $45^{\circ}$ 'de düz bacak kaldırma testi müspet bulunan 25 yaşındaki kadın hastanın, lateral direkt grafi (a) ve T2 ağırlıklı sagittal MR görüntüleme tetkikinde (b) spondiloptozis görüntüsü.

spinal stenoz, spina bifida, transizyonel vertebra, Scheuermann hastalığı vb. patolojiler, yakınmaların nedeni olmayabilir. Dolayısıyla, görüntüleme tetkikleri ile elde edilen verilerin klinik semptom ve bulgularla doğrulanması gereklidir. ${ }^{\left[{ }^{[]}\right.}$Daha önce de ifade edildiği gibi, acil tedavi gerektiren tümör, enfeksiyon, kauda ekina sendromu ve fraktür vb., BA'da kırmızı bayrakların düşünülmesini gerektiren risk faktörleri varlığında, gerekli laboratuvar ve görüntüleme tetkikleri yapılmalıdır. Visseral kaynaklı problemlerin, nadir de olsa BA'ya neden olabileceği akılda tutulmalıdır (Tablo 4). ${ }^{[5,12,28]}$

\section{TEDAVi}

Spesifik BA'da tedavi, altta yatan hastalığa özgüdür ve nedenin ortadan kaldırılmasına yöneliktir. Spesifik olmayan BA tedavisinde ise; ağrının giderilmesi, yeterli 
Tablo 4. Bel ağrısında ayrıcı tanı ${ }^{[5,28]}$

\section{Mekanik}

Non-spesifik (idiyopatik)

Lomber spondilozis

Disk herniyasyonu

Dejeneratif disk hastalığı

Spondilolizis - spondilolistezis

Spinal stenoz

Travma - kırıklar

Faset eklem kaynaklı ağılar

Instabilite

Başarısız bel cerrahisi sendromu

\section{Neoplastik}

Primer

Metastatik

\section{inflamatuvar}

Romatoid artrit, ankilozan spondilit ve diğer spondiloartropatiler

Enfeksiyöz

Vertebra osteomiyelit

Epidural apse

Septik diskitis

Herpes zoster

\section{Metabolik}

Osteoporotik kompresyon kırıkları

Paget hastalığı

\section{Omurgaya yansıyan ağrılar}

Majör vissera, retroperitoneal oluşumlar, ürogenital sistem, aorta vs.

omurga hareketliliğinin sağlanması, fonksiyonel bozukluğun en aza indirilmesi, akut ağı ataklarının ve kronikleşmenin önlenmesi, ağrıyla mücadele etme stratejilerinin geliştirilmesi ve özürlülüğün önüne geçilmesi amaçlanır. ${ }^{[7]}$

\section{Spesifik Olmayan Akut ve Subakut BA}

Tedavide birinci basamak, hastanın bilgilendirilmesi ve eğitimidir. Hastalığın iyileşme ve yineleme oranları, semptom kontrolü için güvenilir yollar, olası rekürrens için tütün kullanımı, obezite ve uygun ağırlık kaldırma vb. risk faktörlerinin belirtilmesi, özel-ileri araştırmaların gereksizliği, izlem için gerekli durumlar (nörolojik semptomlarda ilerleme ya da klinik kötüleşme, başlangıç tedavisi ile iyileşme sağlanamaması, üriner retansiyon veya üriner/anal inkontinans) olduğu belirtilmeli ve bireysel endişeler giderilmelidir. Bu bağlamda, hastalara verilecek olan eğitim broşürlerinin de yardımcı olduğu bilinmektedir. ${ }^{[29,30]}$ Fiziksel aktiviteyi geliştirmeye yönelik kişiye özel programlar oluşturularak, hastanın uzun süren istirahatten kaçınması (yatak istirahati verilecekse bunun iki gün ile sınırlandırılması) ve aktif olması sağlanmalı; ergonomik faktörler konusunda hasta bilgi sahibi olmalıdır. ${ }^{[7,31,32]}$

Farmakolojik tedavi, semptoma yöneliktir. Tüm hareket kısıtıııklarına etki edebilecek geniş etkili bir farmasötik ajan maalesef mevcut değildir. ${ }^{[33]}$ Tedavide ilk seçenek, parasetamol olmalıdır. ${ }^{[7]}$ Steroid olmayan antiinflamatuvar ilaçlar (NSAii'ler), gerek analjezik gerekse antiinflamatuvar etkinliklerinden ötürü, BA medikal tedavisinde sıklıkla tercih edilen ve plaseboya karşı etkinliği kanıtlanmış ilaç grubu olup, yan etki profili nedeni ile dikkatli kullanımları önerilmektedir. ${ }^{[7,34]}$ Miyorelaksan ajanlar da yine akut BA tedavisinde yaygın olarak tercih edilmelerine rağmen, bunların etkinlikleri tartışmalıdır. Kısa süreli ağrı kontrolünde plaseboya karşı etkinlikleri kanıtlanmış olsa da, analjezik ajanlara karşı üstünlüklerini ortaya koyabilecek kanıt düzeyi yeterli çalışma bulunmamaktadır. ${ }^{[7,33]}$ Şiddetli ve/veya yan etkileri nedeni ile diğer analjezik ya da miyorelaksan ilaçların uygulanamadığı olgularda, kısa süreli olarak opioid analjezikler tercih edilebilirlerse de, eğer kullanılır ise, bu ilaçların yan etki profilleri ve bağımlılık geliştirme potansiyelleri akılda tutulmalıdır. ${ }^{[35]}$

Lokal sıcak uygulanmasının, kısa dönem ağrı kontrolü açısından yararı olduğu bilinirken; ${ }^{[36]}$ soğuk uygulama, korse ve ortez kullanımının, kanıta dayalı tıp açısından akut BA tedavisinde yeri yoktur. ${ }^{[29]}$

Spesifik bel egzersizleri, akut dönemde tercih edilmemelidir; bunun yerine esneklik, güçlendirme, koordinasyon ve dayanıklılık sağlayan kişiye özel fiziksel uygunluk programları planlanmalıdır. ${ }^{[7]}$ Egzersiz tedavisine başlamak için ideal zaman konusu ise tartışmalıdır. ${ }^{[37]}$

Epidural steroid enjeksiyonu, traksiyon, elekroterapi, masaj ve akupunkturun, spesifik olmayan akut BA olgularının tedavisinde yarar sağlamadığı bilinmektedir. ${ }^{[29,38,39]}$ Manipülatif tedavilerin, ancak ehliyetli kişiler tarafından uygulandıklarında kısa süreli ve orta derecede yarar sağladıkları belirtilmekle birlikte, ${ }^{[39]}$ şiddetli olgularda ve rekürrensi önlemekteki yerleri açık değildir. ${ }^{[0]}$

Bu hastalarda bir diğer önemli husus da, kronik BA gelişebilme ihtimalidir. Risk altındaki hastaların tekli tedavi yaklaşımlarından yarar görmedikleri bilinmeli ve bu olgulara yoğun multidisipliner rehabilitasyon programları planlanmalıdır. ${ }^{[1]}$

\section{Kronik BA}

Akut ağrıların tedavisinde kullanılan farmakolojik ajanlar, kronik ağrılar için de uygulanır. Ek olarak, tedavi edici etkisi zayıf ve yan etkileri fazla olmasına rağmen, antidepresan etkilerinden bağımsız ve analjezik etkinliği kanıtlanmış olan trisiklik antidepresanlar 
da kronik BA tedavisinde düşük dozlarda uygulanabilmektedir. ${ }^{[7,29]}$ Sedasyon sağlayıcı etkileri sayesinde, ağrıya bağlı uyku bozukluğunun tedavisinde de sinerjistik yarar sağladıkları bilinen antidepresan ilaçların, bazı araştırmalarda plaseboya karşı üstün olmadıkları da belirtilmektedir. ${ }^{[7,42]}$ Bir antiepileptik ajan olan topiramat, kronik BA tedavisinde plaseboya göre etkin bulunmuştur. ${ }^{[43]}$

Tedavide uygulanabilen çeşitli fiziksel tıp modalitelerinin, tek başlarına etkinlikleri tartışmalıdır. Ağrı üzerindeki etkisinden ziyade, uyku bozukluğunun giderilmesi ve gevşeme sağlayıcı özelliklerinden ötürü, "biyo-yararlanım (Biofeedback)" destekleyici bir tedavi yaklaşımı olarak belirtilmektedir. ${ }^{[4]}$ Epidural steroid enjeksiyonlarının kronik BA tedavisinde etkisiz olduğu bilinmekle birlikte, faset eklem enjeksiyonlarının yeri tartışmalıdır. ${ }^{[7,42,44]}$ Manipülatif yaklaşımlar ise, altı aya kadar ağrı ve fonksiyonel kapasitede kısmi yarar sağlamaktadır. ${ }^{43]}$

Kronik BA'nın biyolojik, fizyolojik ve çevresel faktörlerin oluşturduğu kompleks bir durum olması nedeniyle, önerilen tedavi yaklaşımı olan multidisipliner rehabilitasyon programı ile ağrının kontrolü, fonksiyonel kısıtlılığın ortadan kaldırılması, özürlülüğün engellenmesi ve yaşam kalitesinin arttırılması hedeflenir. Bu yaklaşım ile, sağlık kurumlarına başvuru sayısının azalması ve maliyetlerin düşürülmesi de amaçlanır. ${ }^{[45,46]}$ Söz konusu tedavi, hasta eğitimi ve egzersiz programlarından oluşan bel okullarını, psikoterapiyi, bilişsel ve davranışsal tedaviyi, sosyal ve mesleki danışmanlık hizmetlerini ve daha önce sözü edilen biyo-yararlanım tekniklerini kapsar. ${ }^{[7,42,47]}$ Uzman gözetiminde yapılan tedavi planlamasının, başarı oranlarını arttırdığı bilinmelidir. ${ }^{[44]}$ Cerrahi tedavi bahsinde de belirtileceği üzere, bu hastaların tedavisinde uygulanabilecek olan füzyon girişimlerinin, multidisipliner rehabilitasyon yaklaşımından daha etkin olmadığı akılda tutulmalıdır. ${ }^{[48]}$ Konservatif tedavinin olumlu sonuçlarını gösteren bazı ipuçları, Tablo 5'te özetlenmiştir.

Tablo 5. Bel ağrısında konservatif tedavinin olumlu sonuçlarını gösteren belirteçler

Normal fizyolojik durum

Motive ve sağlam bünye

Eğitim düzeyinin yüksekliği (en az 12 yıl temel eğitim)

Omurga ekstansiyonunda bacak ağrısının olmaması

Çapraz düz bacak kaldırma testinin negatif oluşu

Görüntülemede spinal stenozun olmaması

Epidural steroid enjeksiyonuna olumlu yanıt alınması

Nörolojik fonksiyonların 12 hafta içinde düzelmesi

\section{Cerrahi Tedavi}

BA'da kırmızı bayrak olarak adlandırılan belirtilerin varlığı, deformite ve/veya denge kaybı, kronikleşme ve semptomların rekürrensi, omurga cerrahisi konsültasyonunu gerektirir. Cerrahi tedavi; kanser, enfeksiyon, deformite, nörolojik defisitin eşlik ettiği disk herniyasyonu, spinal stenoz (nörojenik klaudikasyon ile), fraktür veya herhangi bir ciddi ve/veya ilerleyici nörolojik kayıp nedeni varlığında endikedir. Fakat nörolojik defisitin eşlik etmediği ciddi dejeneratif değiş̧ikliklerin varlığında, cerrahi tedavinin yeri tartışmalıdır. ${ }^{[9]}$ Tazminat beklentisi, daha önce geçirilmiş başarısız bel cerrahisi, çok seviyeli hastalık varlığı, ağır işçi ve/veya genç erkek olma, tütün kullanımı ve psikososyal faktörlerin, cerrahi tedavi sonuçlarını olumsuz yönde etkileyebileceği bilinmelidir. ${ }^{[43]}$ Aynı zamanda, klinik sonuçları subjektif ve komplikasyon oranı yüksek olabilecek söz konusu girişimlerin etkinliğini gözlemlemek için, randomize kontrollü çalışmalara ihtiyaç duyulmaktadır. ${ }^{[50]}$

\section{PROGNOZ}

Akut BA ataklarının büyük çoğunluğunun kendiliğinden iyileştiği bilinmektedir. Bunların \%30-60'ı bir hafta içerisinde, \%60-90'ı altı hafta içerisinde, \%95'i ise on iki hafta içerisinde gerilemekte ve fonksiyonel iyileşme sağlanmaktadır. ${ }^{[7,15,16,47,51]}$ Hastaların \%68-86'sı ilk bir ay, \%90'ı ise iki ay içerisinde işe geri dönmektedir. ${ }^{[52]}$ Rekürrens sıklığı ise, ilk altı ay içerisinde \%40, bir yıl içerisinde $\% 73$, üç yıl içerisinde ise $\% 84$ olarak bildirilmektedir. ${ }^{[53]}$ BA nedeni ile hekime başvuran hastaların \%35-80'inde, çeşitli şiddetlerde ağrının devam ettiği ve özürlülük oranının \%10'lara ulaştığı belirtilmektedir. ${ }^{[15,16,53]}$ Bilindiği gibi, BA'nın kronikleşmesi karmaşık bir süreçtir ve bunda kişisel, psikososyal ve mesleksel faktörler rol oynar. ${ }^{[7]}$ Özellikle ağrı hafifletici davranışların bilinmemesi, fonksiyonel bozukluk varlığı, genel sağlık durumunun kötü olması ve psikiyatrik komorbiditeler, ağrının inatçı hal almasına yol açar. ${ }^{[11]}$

\section{KORUNMA}

Toplumda sık görülmesi ve önemli bir sağlık sorunu olması nedeniyle, BA'yı önleyici yöntemlerin yeri, koruyucu hekimlik açısından önem arz etmektedir. Korunma, sağlıklı bireylerde BA gelişmesini önlemeye (primer) ya da BA rekürrenslerini ve kronikleşmesini engellemeye (sekonder) yönelik olarak uygulanabilir. ${ }^{[54]}$ Biyomekanik ve patofizyolojik açıdan, söz konusu önlemler sağlam temeller üzerine inşa edilmiş olsalar da, bunların klinik yeterliliklerini gösteren kanıt düzeyi yüksek çalışma maalesef yoktur. ${ }^{[54]}$ Bireysel, psikososyal, çalışma koşulları vb. 
BA geliştirebilecek risk faktörlerinin ortaya konularak düzenlenmesinin, ağrı sıklık ve yoğunluğunun azalmasına katkı sağlayabileceği bilinmektedir. Bel okulu ve lomber desteklerin ağrıy önlemede yeterli olmadığı, ergonomik önlemler ve egzersiz programlarının da yararlarının tartışmalı olduğu belirtilse de, söz konusu araştırmaların kanıt düzeylerinin yeterli olmadığı unutulmamalıdır. ${ }^{[5,55]}$

\section{SONUÇ}

BA, toplumda sık görülen önemli bir halk sağlığı sorunudur. l̇yi bir öykü ve fizik inceleme, problemi ortaya koymada ve ayırıcı tanının yapılmasında oldukça değerlidir. Sanılanın aksine, gerek tıbbi tedavi yöntemlerinin daha başarılı gerekse de prognozun daha iyi olduğu bilinen basit akut BA tanısında başarının anahtarının, hastalara güven vermek olduğu akılda tutulmalıdır. Tedavi yaklaşımlarının halen tartışma$\mathrm{I}$, konservatif ve cerrahi tedavi sonuçlarının memnun edici olmadığı kronik BA tanısında ise, tedavi planlanırken olumsuz prognostik faktörlerinin varlığı gözden geçirilmeli, beklentiler hasta ile tartışılarak tedavi planı bireyselleştirilmelidir.

\section{KAYNAKLAR}

1. Frymoyer JW, Cats-Baril WL. An overview of the incidences and costs of low back pain. Orthop Clin North Am 1991;22(2):263-71.

2. Manchikanti L, Singh V, Falco FJ, Benyamin RM, Hirsch JA. Epidemiology of low back pain in adults. Neuromodulation 2014;17 Suppl 2:3-10. CrossRef

3. Gilgil E, Kaçar C, Bütün B, Tuncer T, Urhan S, Yildirim C, Sünbüloglu G, Arikan V, Tekeoglu I, Oksüz MC, Dündar U. Prevalence of low back pain in a developing urban setting. Spine (Phila Pa 1976) 2005;30(9):1093-8.

4. Dündar PE, Özyurt BC, Özmen D. Manisa'da kırsal bir bölgede kadınlarda bel ağrısı sıklığı; ev işleri ve diğer faktörlerle ilişkisi. Ağrı Dergisi 2006;18:51-6.

5. Şenköylü A. Bel ağrısında kırmızı bayraklar. Türk Fiz Tıp Rehab Derg 2011;57 (Kasım):0-0.

6. Patel S, Friede T, Froud R, Evans DW, Underwood M. Systematic review of randomized controlled trials of clinical prediction rules for physical therapy in low back pain. Spine (Phila Pa 1976) 2013;38(9):762-9. CrossRef

7. Kutsal YG, İnanıcı F, Oğuz KK, Alanay A, Palaoğlu S. Bel ağrıları. Hacettepe Tıp Dergisi 2008;39:180-93.

8. Deyo RA, Rainville J, Kent DL. What can the history and physical examination tell us about low back pain? JAMA 1992;268(6):760-5.

9. van Tulder MW, Assendelft WJ, Koes BW, Bouter LM. Spinal radiographic findings and nonspecific low back pain. A systematic review of observational studies. Spine (Phila $\mathrm{Pa}$ 1976) 1997;22(4):427-34.

10. Chou R, Fu R, Carrino JA, Deyo RA. Imaging strategies for low-back pain: systematic review and meta-analysis. Lancet 2009;373(9662):463-72. CrossRef
11. Chou R, Shekelle P. Will this patient develop persistent disabling low back pain? JAMA 2010;303(13):1295-302. CrossRef

12. Hochschuler $\mathrm{SH}$. Diagnostic studies in clinical practice. Orthop Clin North Am 1983;14(3):517-26.

13. Kinkade S. Evaluation and treatment of acute low back pain. Am Fam Physician 2007;75(8):1181-8.

14. Back pain and sciatica. New Engl J Med 1988;319(5):311-2.

15. Deyo RA, Weinstein JN. Low back pain. New Engl J Med 2001;344(5):363-70.

16. Carragee EJ. Clinical practice. Persistent low back pain. New Engl J Med 2005;352(18):1891-8.

17. Diamond S, Borenstein D. Chronic low back pain in a working-age adult. Best Pract Res Clin Rheumatol 2006;20(4):707-20.

18. Jarvik JG, Deyo RA. Diagnostic evaluation of low back pain with emphasis on imaging. Ann Intern Med 2002;137(7):586-97.

19. Vroomen PC, de Krom MC, Knottnerus JA. Diagnostic value of history and physical examination in patients suspected of sciatica due to disc herniation: a systematic review. J Neurol 1999;246(10):899-906.

20. Görgülü $A$, Çobanoğlu $S$, Özsüer $H$, Şimşek $O$, Ekuklu G. Lomber disk herniasyonunda siyatik sinir germe testleri'nin önemi. Türk Nöroşirürji Dergisi 2000;10(1):26-31.

21. Kosteljanetz M, Bang F, Schmidt-Olsen S. The clinical significance of straight-leg raising (Lasegue's sign) in the diagnosis of prolapsed lumbar disc. Interobserver variation and correlation with surgical finding. Spine (Phila Pa 1976) 1988;13(4):393-5.

22. Waddell G, McCulloch JA, Kummel E, Venner RM. Nonorganic physical signs in low-back pain. Spine (Phila $\mathrm{Pa}$ 1976) $1980 ; 5(2): 117-25$.

23. Blom A, Taylor A, Whitehouse S, Orr B, Smith E. A new sign of inappropriate lower back pain. Ann R Coll Surg Engl 2002;84(5):342-3.

24. Portenoy RK, Lipton RB, Foley KM. Back pain in the cancer patient: an algorithm for evaluation and management. Neurology 1987;37(1):134-8.

25. Weber $\mathrm{H}$, Holme I, Amlie E. The natural course of acute sciatica with nerve root symptoms in a double-blind placebocontrolled trial evaluating the effect of piroxicam. Spine (Phila Pa 1976) 1993;18(11):1433-8.

26. Jensen MC, Brant-Zawadzki MN, Obuchowski N, Modic MT, Malkasian D, Ross JS. Magnetic resonance imaging of the lumbar spine in people without back pain. New Engl J Med 1994;331(2):69-73.

27. Iwasaki $H$, Yoshida M, Yamada $H$, Hashizume $H$, Minamide $A$, Nakagawa Y, Kawai M, Tsutsui S. A new electrophysiological method for the diagnosis of extraforaminal stenosis at L5-s1. Asian Spine J 2014;8(2):145-9. CrossRef

28. Dixit R. Low back pain. In: Firestein GS, Budd RC, Gabriel SE, Mclnnes IB, O'Dell JR, editors. Kelley's Textbook of Rheumatology, 9th ed. Philadelphia, PA. Saunders, Elsevier; 2013. p.665-82.

29. Chou R, Qaseem A, Snow V, Casey D, Cross JT Jr, Shekelle $P$, Owens DK; Clinical Efficacy Assessment Subcommittee of the American College of Physicians; American College of Physicians; American Pain Society Low Back Pain Guidelines Panel. Diagnosis and treatment of low back pain: a joint clinical practice guideline from the American College of Physicians and the American Pain Society. Ann Intern Med 2007;147(7):478-91. 
30. Hagen KB, Hilde G, Jamtvedt G, Winnem M. Bed rest for acute low-back pain and sciatica. Cochrane Database Syst Rev 2004(4):CD001254.

31. Dahm KT, Brurberg KG, Jamtvedt G, Hagen KB. Advice to rest in bed versus advice to stay active for acute low-back pain and sciatica. Cochrane Database Syst Rev 2010(6):CD007612. CrossRef

32. Krismer M, van Tulder M; Low Back Pain Group of the Bone and Joint Health Strategies for Europe Project. Strategies for prevention and management of musculoskeletal conditions. Low back pain (non-specific). Best Pract Res Clin Rheumatol 2007;21(1):77-91.

33. Park SY, An HS, Moon SH, Lee HM, Suh SW, Chen D, Jeon $\mathrm{JH}$. Neuropathic Pain Components in Patients with Lumbar Spinal Stenosis. Yonsei Med J 2015;56(4):1044-50. CrossRef

34. Chou R, Huffman LH; American Pain Society; American College of Physicians. Medications for acute and chronic low back pain: a review of the evidence for an American Pain Society/American College of Physicians clinical practice guideline. Ann Intern Med 2007;147(7):505-14.

35. Hazard RG. Low-back and neck pain diagnosis and treatment. Am J Phys Med Rehabil 2007;86(1 Suppl): S59-68.

36. Negrini S, Giovannoni S, Minozzi S, Barneschi G, Bonaiuti D, Bussotti A, D‘Arienzo M, Di Lorenzo N, Mannoni A, Mattioli S, Modena V, Padua L, Serafini F, Violante FS. Diagnostic therapeutic flow-charts for low back pain patients: the Italian clinical guidelines. Eura Medicophys 2006;42(2):151-70.

37. Assendelft WJ, Morton SC, Yu EI, Suttorp MJ, Shekelle PG. Spinal manipulative therapy for low back pain. A metaanalysis of effectiveness relative to other therapies. Ann Int Med 2003;138(11):871-81.

38. Wegner I, Widyahening IS, van Tulder MW, Blomberg SE, de Vet HC, Bronfort G, Bouter LM, van der Heijden GJ. Traction for low-back pain with or without sciatica. Cochrane Database Syst Rev 2013;8:CD003010. CrossRef

39. van Tulder M, Koes B. Low back pain (chronic). Clin Evid 2006;15:1634-53.

40. Cherkin DC, Deyo RA, Battié M, Street J, Barlow W. A comparison of physical therapy, chiropractic manipulation, and provision of an educational booklet for the treatment of patients with low back pain. $N$ Engl J Med 1998;339(15):1021-9.

41. Grabois M. Management of chronic low back pain. Am J Phys Med Rehabil 2005;84(3 Suppl):S29-41.

42. van der Windt D, Hay E, Jellema P, Main C. Psychosocial interventions for low back pain in primary care: lessons learned from recent trials. Spine (Phila Pa 1976) 2008;33(1):81-9. CrossRef

43. Herndon CM, Zoberi KS, Gardner BJ. Common questions about chronic low back pain. Am Fam Physician 2015;91(10):708-14.
44. Ribeiro LH, Jennings $F$, Jones A, Furtado R, Natour J. Effectiveness of a back school program in low back pain. Clin Exp Rheumatol 2008;26(1):81-8.

45. Jarvik JG, Gold LS, Comstock BA, Heagerty PJ, Rundell SD, Turner JA, Avins AL, Bauer Z, Bresnahan BW, Friedly JL, James K, Kessler L, Nedeljkovic SS, Nerenz DR, Shi X, Sullivan SD, Chan L, Schwalb JM, Deyo RA. Association of early imaging for back pain with clinical outcomes in older adults. JAMA 2015;313(11):1143-53. CrossRef

46. Chou R, Loeser JD, Owens DK, Rosenquist RW, Atlas SJ, Baisden J, Carragee EJ, Grabois M, Murphy DR, Resnick DK, Stanos SP, Shaffer WO, Wall EM; American Pain Society Low Back Pain Guideline Panel. Interventional therapies, surgery, and interdisciplinary rehabilitation for low back pain: an evidence-based clinical practice guideline from the American Pain Society. Spine (Phila Pa 1976) 2009;34(10):1066-77. CrossRef

47. Haldeman S, Dagenais S. What have we learned about the evidence-informed management of chronic low back pain? Spine J 2008;8(1):266-77. CrossRef

48. Peul WC, van Houwelingen $\mathrm{HC}$, van den Hout WB, Brand R, Eekhof JA, Tans JT, Thomeer RT, Koes BW; Leiden-The Hague Spine Intervention Prognostic Study Group. Surgery versus prolonged conservative treatment for sciatica. New Engl J Med 2007;356(22):2245-56.

49. Chou R, Baisden J, Carragee EJ, Resnick DK, Shaffer WO, Loeser JD. Surgery for low back pain: a review of the evidence for an American Pain Society Clinical Practice Guideline. Spine (Phila Pa 1976) 2009;34(10):1094-109. CrossRef

50. Deyo RA, Nachemson A, Mirza SK. Spinal-fusion surgery - the case for restraint. New Engl J Med 2004;350(7):722-6.

51. Carragee EJ, Hannibal M. Diagnostic evaluation of low back pain. Orthop Clin North Am 2004;35(1):7-16.

52. Pengel LH, Herbert RD, Maher CG, Refshauge KM. Acute low back pain: systematic review of its prognosis. BMJ 2003;327(7410):323.

53. Carey TS, Garrett JM, Jackman A, Hadler N. Recurrence and care seeking after acute back pain: results of a long-term follow-up study. North Carolina Back Pain Project. Med Care 1999;37(2):157-64.

54. Linton SJ, van Tulder MW. Preventive interventions for back and neck pain problems: what is the evidence? Spine (Phila Pa 1976) 2001;26(7):778-87.

55. van Tulder MW, Koes BW, Bouter LM. Conservative treatment of acute and chronic nonspecific low back pain. A systematic review of randomized controlled trials of the most common interventions. Spine (Phila Pa 1976) 1997;22(18):2128-56. 